\title{
Estimating chronic disease rates in Canada: which population-wide denominator to use?
}

\section{J. Ellison, MPH (1); C. Nagamuthu, MPH (2); S. Vanderloo, MSc (3); B. McRae (1); C. Waters, BSc (1)}

This article has been peer reviewed.

Tweet this article

\begin{abstract}
Introduction: Chronic disease rates are produced from the Public Health Agency of Canada's Canadian Chronic Disease Surveillance System (CCDSS) using administrative health data from provincial/territorial health ministries. Denominators for these rates are based on estimates of populations derived from health insurance files. However, these data may not be accessible to all researchers. Another source for population size estimates is the Statistics Canada census. The purpose of our study was to calculate the major differences between the CCDSS and Statistics Canada's population denominators and to identify the sources or reasons for the potential differences between these data sources.
\end{abstract}

Methods: We compared the 2009 denominators from the CCDSS and Statistics Canada. The CCDSS denominator was adjusted for the growth components (births, deaths, emigration and immigration) from Statistics Canada's census data.

Results: The unadjusted CCDSS denominator was 34429 804, 3.2\% higher than Statistics Canada's estimate of population in 2009. After the CCDSS denominator was adjusted for the growth components, the difference between the two estimates was reduced to 431323 people, a difference of $1.3 \%$. The CCDSS overestimates the population relative to Statistics Canada overall. The largest difference between the two estimates was from the migrant growth component, while the smallest was from the emigrant component.

Conclusion: By using data descriptions by data source, researchers can make decisions about which population to use in their calculations of disease frequency.

Keywords: Canadian Chronic Disease Surveillance System, denominator, census, population estimates Canada, disease surveillance, measures of disease frequency, administrative health data

\section{Introduction}

Many countries, including Canada, Australia, France and Italy, have administrative health databases that are established and/or supported by governments that provide universal medical care. ${ }^{1}$ Administrative health data refer to data routinely collected through the administration of health care services. ${ }^{2}$ These data can be used for health service planning, reporting performance evaluations, clinical decision making and answering research questions. ${ }^{2}$ Administrative data can also be used to conduct disease surveillance..$^{3-7}$ Measures of disease frequency, such as prevalence, incidence and mortality rates, can be used to describe the burden of disease among a population. With this information, policy, public health and health economics professionals can make informed decisions. Therefore, it is important that researchers choose appropriate denominators to calculate these measures. Calculations of incidence, prevalence and mortality rates are composed of the numerator and denominator. Improper selection of the total population can lead to biased estimates of the rates of occurrence of disease and death. ${ }^{8}$

\section{Highlights}

- Accurate population estimates are important when measuring the burden of chronic diseases.

- The authors calculated the major differences between the Canadian Chronic Disease Surveillance System and Statistics Canada's population denominators to find the best sources and the reasons for any differences between them.

- The unadjusted CCDSS denominator was 34429804 , 3.2\% higher than Statistics Canada's estimate of population in 2009. After the CCDSS denominator was adjusted for the growth components, the difference between the two estimates was reduced to 431323 people, a difference of $1.3 \%$.

- The largest difference between the two estimates was from the migrant growth component, while the smallest was from the emigrant component.

Estimates of populations are often the most appropriate estimate available of the number of people at risk for an outcome.

One source of denominator estimates is Statistics Canada. Statistics Canada conducts a census every five years and collects data from citizens (including permanent residents), non-permanent residents and their families living in Canada. ${ }^{9}$ Most of the population self-enumerates by completing census surveys by mail or electronically. ${ }^{9}$

The objective of the census is to provide information about the demographic and

\section{Author references:}

1. Centre for Chronic Disease Prevention, Public Health Agency of Canada, Ottawa, Ontario, Canada

2. Department of Public Health Sciences, School of Public Health, University of Alberta, Edmonton, Alberta, Canada

3. Clinical Epidemiology Program, Ottawa Hospital Research Institute, Ottawa, Ontario, Canada

Correspondence: Joellyn Ellison, Centre for Chronic Disease Prevention, Public Health Agency of Canada, 785 Carling Avenue, 6th Floor, 623 A-3, Ottawa, ON K1A 0K9; Tel: 613-797-8721; Fax: 613-941-2057; Email: joellyn.ellison@phac-aspc.gc.ca 
social characteristics of the Canadian population. ${ }^{9}$ Estimates are then derived from the census and adjusted for under- and overcoverage. ${ }^{10}$

Another source for denominator estimates is the Public Health Agency of Canada's (PHAC) Canadian Chronic Disease Surveillance System (CCDSS). The CCDSS is a network of federal and provincial/territorial health insurance surveillance systems supported by PHAC. Denominator estimates are based on the number of people who hold valid health insurance at any given time during the fiscal year. The CCDSS is used to determine the number of Canadians living with chronic disease via interactions with the health care system, based on diagnostic and procedural codes; it adds to the breadth of information about disease burden in Canada. The system includes aggregate information for the following chronic diseases: diabetes, hypertension, ischemic heart disease, acute myocardial infarction, heart failure, mental illness, osteoporosis, asthma, chronic pulmonary disease, multiple sclerosis and parkinsonism.

This study is the first to compare the CCDSS denominator derived from national administrative health data with estimates of population from Statistics Canada. However, an Alberta Health and Wellness provincial-level study compared Alberta population counts, as covered under the Alberta Health Care Insurance Plan (AHCIP) Registry, and the 2006 census. ${ }^{11}$ The study showed that the 2006/07 AHCIP Registry was underestimated by $0.0988 \%$ (3249/3287 101) compared to Statistics Canada's estimate of population. However, as of June 2015, the AHCIP estimate was higher than those from Statistics Canada. ${ }^{12}$ PHAC conducted a similar analysis in 2012, comparing the CCDSS denominator (fiscal year 2006/2007) and Statistics Canada's estimate of population (census year 2006), and found an overestimate for the CCDSS denominator of about $3.9 \%$ (955 358/24 258 902). However, this difference was difficult to interpret as data for Quebec and Newfoundland and Labrador were excluded for data quality reasons; Statistics Canada estimates were used instead. For Quebec, the data for Canadians without the disease were not available at the Institute National de Santé Publique du Québec (INSPQ), and for Newfoundland and Labrador the health insurance cards prior to 2008 did not have an expiration date, resulting in duplicate records in the medical care plan database.

The purpose of our study was to calculate the major differences between the CCDSS and Statistics Canada's estimate of population and to identify the sources or reasons for the potential differences between the CCDSS and Statistics Canada population denominators. Our objective was to inform researcher and analyst decisions about which estimate of population or denominator to use in disease frequency calculations.

\section{Methods}

\section{Data sources}

The CCDSS uses provincial/territorial administrative databases to track chronic diseases among Canadians. ${ }^{4-7}$ The CCDSS was developed by linking three administrative databases with individuals' unique lifetime identifiers. ${ }^{7}$ The three databases include the (1) health insurance registry file; (2) fee-for-service and some shadowbilled physician services file; and (3) hospital files that capture hospital-based acute care interactions through diagnostic and procedural codes. ${ }^{7}$ These health databases were records of health care interactions for residents who are eligible to receive provincial/territorial health care. ${ }^{7}$ The health insurance file contains demographic information, including a unique lifetime identifier, linking the three databases together. ${ }^{13}$

This health insurance registry also included a record for anyone who was alive and eligible to receive health care at any point in the fiscal year. Therefore, people who have died are captured in the year of their death. The federal government funds programs to provide subgroups of the population (First Nations and Inuit people, refugee protection claimants, eligible veterans, federal penitentiary inmates and serving members of the Canadian forces and the RCMP [Royal Canadian Mounted Police]) with health services and benefits that are not insured by provincial/territorial governments. These include coverage for dental and vision care, medical supplies and certain drugs. ${ }^{14,15}$ First Nations and Inuit people still hold provincial health insurance and were captured by the CCDSS through the health insurance registry file.
Generally, members of the Canadian forces, RCMP and inmates of federal prisons ${ }^{15}$ are not captured by the CCDSS (approximately 110000 people per year). The CCDSS denominator counts were obtained from each province's and territory's data submissions to PHAC as of November 2015, up to the $2009 / 2010$ fiscal year. Data from this fiscal year were used as they were the latest available at the time of analyses. The aggregate datasets were composed of residents with valid health care insurance at any point during the fiscal year and included residents who died within the same year, by disease and demographic variables, such as age and sex.

\section{Statistics Canada's estimates of population}

Statistics Canada's estimates of population are derived from census data. Although Statistics Canada aims to enumerate the Canadian population on census day by collecting data at a single point in time (a cross-sectional view of the population) the census misses and over-counts some fraction of the population (2.7\%) (868 657/32 500 000). ${ }^{16}$ Some people may not be counted because they were away during the enumeration period or lived in a collective dwelling that provides care or assistance services, while others were counted more than once (e.g. students living away from home who were enumerated by themselves and their parents). ${ }^{16}$ This is described as under- and over-coverage. ${ }^{17,18}$

Statistics Canada conducts postcensal coverage studies using a representative sample of people to determine the number of people missed or counted more than once during enumeration. ${ }^{19}$ The results of these studies are combined with the census estimates to produce current estimates of population, using postcensal and intercensal estimates. ${ }^{10}$ Intercensal estimates are estimates of the population during the period between two censuses. ${ }^{10}$ These adjustments render near complete estimates of population coverage.

\section{Study cohorts}

We compared the CCDSS denominator from fiscal year 2009/10 with Statistics Canada's estimate of population for $2009^{20}$ by age group. The age-at-reference date for the CCDSS denominator was March 31 and July 1 for the Statistics Canada estimate of population. The CCDSS denominator was adjusted for the growth components (births, deaths, emigration 
TABLE 1

CCDSS adjusted denominator, based on Statistics Canada methods, ${ }^{22}$ Canada, 2009

\begin{tabular}{|lcc|}
\multicolumn{1}{|c}{ Growth component } & Adjustment & $\begin{array}{c}\text { Magnitude of the } \\
\text { adjusted result }\end{array}$ \\
\hline Births $^{23}$ & $379373 / 3$ & 126457 \\
\hline Deaths $^{23}$ & $237138 / 3$ & 79046 \\
\hline Immigrants $^{24}$ & $270581 / 3$ & 90193 \\
\hline Emigrants $^{24}$ & $52335 / 3$ & 17445 \\
\hline Net non-permanent residents $^{24}$ & 34531 & 34531 \\
\hline Migrants $^{24,25}$ & Out: $(259234 \times 1.5)-$ & 302440 \\
\hline
\end{tabular}

Abbreviation: CCDSS, Canadian Chronic Disease Surveillance System.

Notes: CCDSS adjusted denominator $(n=33779692)=$ CCDSS count $(n=34429$ 804) minus births $(n=126$ 457) minus deaths $(n=79046)$ minus immigrants $(n=90193)$ minus emigrants $(n=17445)$ minus net non-permanent residents ( $n=34$ 531) minus in-and-out-migrants $(n=302440)$.

After CCDSS adjustment, the difference between the two denominators is 431296 (1.3\%).

and immigration) using files from census data (Table 1). ${ }^{21}$ The CCDSS denominator data included interprovincial migration (i.e. residents who migrate between provinces and territories were counted more than once), whereas Statistics Canada's estimates of population were already adjusted for interprovincial migration, net immigration and deaths. ${ }^{26}$

We ran analyses using SAS Enterprise Guide version 4.1 (SAS Institute Inc., Cary, NC, USA). To illustrate the differences between the CCDSS and Statistics Canada's estimate of population, our analyses were conducted with and without the growth components for the CCDSS denominator. See Table 2 for a summary of the data definitions by source.

\section{Statistical methods}

The overall percent difference between the CCDSS denominator and Statistics Canada's estimate of population, for Canada and by province/territory, was calculated as

[(CCDSS denominator - Statistics Canada's estimate of population) / Statistics Canada's estimate of population] $\times 100$.

To examine the largest impact on the rates, among all age groups, using both data sources, we compared diabetes prevalence, incidence and mortality rates that were calculated using the CCDSS denominator and Statistics Canada's estimate of population. We used the CCDSS data to

TABLE 2

Data descriptions by source (CCDSS and Statistics Canada estimates of population), 2009

\begin{tabular}{lll} 
Data sources & \multicolumn{1}{c}{ PHAC's CCDSS denominator } & Statistics Canada's estimates of population \\
\hline $\begin{array}{l}\text { Estimate } \\
\text { type }\end{array}$ & $\begin{array}{l}\text { Period estimate (Canadians with valid } \\
\text { health insurance during the fiscal year) }\end{array}$ & $\begin{array}{l}\text { Point in time estimate (estimate of the } \\
\text { number of Canadians from the Census) }\end{array}$ \\
\hline Inclusions & $\begin{array}{l}\text { 1) Deaths that occur during the fiscal year } \\
\text { 2) Canadians who migrate in Canada } \\
\text { during the fiscal year (double-counting) }\end{array}$ & $\begin{array}{l}\text { 1) A representative sample of Canadians } \\
\text { 2) Adjustments for growth components } \\
\text { (births, deaths, emigration, and immigration) } \\
\text { and those missed (away during enumeration) } \\
\text { or double-counted (students away from home) }\end{array}$ \\
\hline Exclusions & $\begin{array}{l}\text { Canadians covered under federal } \\
\text { insurance }\end{array}$ & $\begin{array}{l}\text { Canadians who are away during enumeration or } \\
\text { lived in a collective dwelling, but adjusted for }\end{array}$ \\
\hline Use/role & $\begin{array}{l}\text { Is a companion for the CCDSS numerator } \\
\text { (Canadians exposed to the health event } \\
\text { are included in the denominator) }\end{array}$ & $\begin{array}{l}\text { Is a companion for a numerator consisting of } \\
\text { Canadians who were exposed to a health event }\end{array}$ \\
\hline
\end{tabular}

Abbreviations: CCDSS, Canadian Chronic Disease Surveillance System; PHAC, Public Health Agency of Canada. count the number of all-cause deaths across the provinces/territories. We calculated rates for estimates of population from both data sources for the population denominator;

- Diabetes prevalence $=$ [Total number of individuals with a case date during the capture period or prevalent cases / Total number of individuals with valid health insurance during the capture period] $\times 100$ or Diabetes prevalence $=$ [Total number of individuals with a case date during the capture period or prevalent cases / Statistics Canada's estimate of population] $\times 100$

- Diabetes incidence $=$ [Total number of incident cases / (Total number of individuals with valid health insurance during the capture period - Prevalent cases at the beginning of the fiscal year)] $\times 1000$ or Diabetes incidence $=$ [Total number of incident cases / (Statistics Canada's estimate of population - Prevalent cases at the beginning of the fiscal year) ] $\times 1000$

- All-cause mortality $=$ [Total number of CCDSS deaths / Total CCDSS population] $\times 100000$ or All-cause mortality $=$ [Total number of CCDSS deaths / Statistics Canada's estimate of population] $\times 100000$

These rates were calculated using SAS macros (pre-programmed codes), and the counts randomly rounded. ${ }^{26}$ Mortality data for Statistics Canada's estimate of population were obtained from vital statistics files for 2009 (to match the CCDSS 2009/10 fiscal year). ${ }^{27}$ To assess the impact of mortality rates with both sources of denominators on the life expectancy calculation, we compared the CCDSS denominator life expectancy by sex and age group for each disease tracked by the CCDSS to Statistics Canada's estimate of population life expectancy. We stratified the CCDSS data by sex and 18 standard age groups $(1-4,5-9, \ldots 80-84, \geq 85$ years). Next we created a life table for the number of people who had a diagnostic code for a disease and the number of people who did not. The Gompertz function was used to provide an accurate estimate of life expectancy for the last open-ended age interval ( $\geq 85$ ), to close the life table..$^{28,29}$

Since disease status was not available for infants younger than one year, the 2004 to 2006 sex-specific death rates for the Canadian population, from Statistics 
Canada, were used to model the mortality experience of infants with and without the disease. The 0- to 1-year sex-specific death rates, used to construct the life table, represented infants without the disease. Infant death rates for the disease were unavailable. Because the 0 to 1 age group experienced a high rate of mortality, we assumed that the number of infants with and without the disease would be about the same.

\section{Results}

Our findings show that CCDSS and Statistics Canada estimates of population differ. Specifically, the CCDSS overestimates the population relative to Statistics Canada overall.

The largest difference between the two estimates was contributed by the migrant growth component (302440), while the smallest was from the emigrant component (17445) (Table 1). When deaths were included in the CCDSS denominator, we observed 1081408 more people in the CCDSS denominator (34429804) compared to Statistics Canada's estimate of population (33348396), a + 3.2\% (1081408/33348396) difference (Table 3 ).

After the CCDSS denominator was adjusted for the growth components, we observed 431296 more people in the CCDSS denominator (33779692) compared to Statistics Canada's estimate of population (33348396), a + 1.3\% (431296/33 348396) difference (Table 1). The largest difference between the two was observed among the 85 -and-older age group ( $+20.5 \%$; $126453 / 617160)$ and the smallest among the 20 to 24 age group $(-0.8 \%$; $17757 / 2322497$ ) (Table 3).

By province/territory, the largest difference between the two was observed for Northwest Territories (+13.0\%; 5600/42965), whereas the smallest was for Quebec (+0.5\%; 37595/7737335) (Table 4). A similar pattern was observed after excluding deaths from the CCDSS denominator. However, after adjustment for the growth components, the difference was reduced to 431296 people $(\Delta 1.3 \% ; 431296 / 33348396)$ (Table 1).

For all Canadians, the CCDSS denominator diabetes prevalence rate $(7.2 \%$; $2489520 / 34429804)$ was $4.00 \%(-0.3 / 7.5)$ lower than Statistics Canada's estimate of
TABLE 3

Estimates of population by age group, Canada, 2009

\begin{tabular}{|c|c|c|c|}
\hline Age groups in years & CCDSS denominator $^{\mathrm{a}}$ & $\begin{array}{c}\text { Statistics Canada's } \\
\text { estimates of } \\
\text { population }^{\text {b }}\end{array}$ & Percent difference, $\%$ \\
\hline $1-4$ & 1540368 & 1464423 & 5.2 \\
\hline $5-9$ & 1845877 & 1798812 & 2.6 \\
\hline $10-14$ & 2009792 & 1972894 & 1.9 \\
\hline $15-19$ & 2264299 & 2250692 & 0.6 \\
\hline $20-24$ & 2304740 & 2322497 & -0.8 \\
\hline $25-29$ & 2358661 & 2348492 & 0.4 \\
\hline $30-34$ & 2310455 & 2258092 & 2.3 \\
\hline $35-39$ & 2377282 & 2297458 & 3.5 \\
\hline $40-44$ & 2512797 & 2480011 & 1.3 \\
\hline $45-49$ & 2858523 & 2787129 & 2.6 \\
\hline $50-54$ & 2686876 & 2573413 & 4.4 \\
\hline $55-59$ & 2322492 & 2215710 & 4.8 \\
\hline $60-64$ & 1999094 & 1888212 & 5.9 \\
\hline $65-69$ & 1480822 & 1406971 & 5.2 \\
\hline $70-74$ & 1137703 & 1080535 & 5.3 \\
\hline $75-79$ & 947527 & 909136 & 4.2 \\
\hline $80-84$ & 728883 & 676759 & 7.7 \\
\hline$\geq 85$ & 743613 & 617160 & 20.5 \\
\hline All ages & 34429804 & 33348396 & 3.2 \\
\hline
\end{tabular}

a CCDSS denominator data were contributed by provinces and territories, as of November 2015 (v2014).

${ }^{\mathrm{b}}$ Statistics Canada's estimates of population were postcensal (2006 Census). ${ }^{20}$

TABLE 4

Estimates of population by province/territory, Canada, 2009

\begin{tabular}{|c|c|c|c|}
\hline Province/Territory & $\begin{array}{c}\text { CCDSS } \\
\text { denominator }^{\mathrm{a}}\end{array}$ & $\begin{array}{l}\text { Statistics Canada's } \\
\text { estimates of population }\end{array}$ & $\begin{array}{c}\text { Percent } \\
\text { difference, } \%\end{array}$ \\
\hline $\begin{array}{l}\text { Newfoundland and } \\
\text { Labrador }\end{array}$ & 537862 & 504141 & 6.7 \\
\hline Prince Edward Island & 148911 & 139593 & 6.7 \\
\hline Nova Scotia & 989707 & 931622 & 6.2 \\
\hline New Brunswick & 755910 & 742506 & 1.8 \\
\hline Quebec & 7774930 & 7737335 & 0.5 \\
\hline Ontario & 13563855 & 12928815 & 4.9 \\
\hline Manitoba & 1239544 & 1204232 & 2.9 \\
\hline Saskatchewan & 1067733 & 1015590 & 5.1 \\
\hline Alberta & 3711026 & 3621681 & 2.5 \\
\hline British Columbia & 4524374 & 4415160 & 2.5 \\
\hline Yukon & 33745 & 33342 & 1.2 \\
\hline Northwest Territories & 48565 & 42965 & 13.0 \\
\hline Nunavut & 33642 & 31414 & 7.1 \\
\hline Canada & 34429804 & 33348396 & 3.2 \\
\hline
\end{tabular}

a CCDSS denominator data were contributed by provinces and territories, as of November 2015 (v2014).

${ }^{\text {b }}$ Statistics Canada's estimates of population were postcensal (2006 Census). ${ }^{20}$ 
population rate $(7.5 \% ; 2489520 / 33348396)$ and $3.03 \%(-0.2 / 6.6)$ lower for incidence rates with the CCDSS denominator (6.4 per 1000; 218240/34211 564) and Statistics Canada's estimates of population (6.6 per $1000 ; 218$ 240/33 130 156). The CCDSS denominator total all-cause mortality rate (669.2 per 100000; 230408/34429804) was $3.1 \%(-21.7 / 690.9)$ lower than Statistics Canada's estimate of population rate (690.9 per 100 000; 230 408/33348396; Table 5). The life expectancy at birth was 82.9 years for the CCDSS denominator and 81.2 years for Statistics Canada's estimate of population.

\section{Discussion}

A difference between the CCDSS denominator and Statistics Canada's estimate of population is that the latter provides a cross-sectional view of the population at a specific time period (period of enumeration), whereas the CCDSS denominators have been used to provide an estimate of the population exposed, or "at risk," over an annual period. Although prevalence and incidence rates can be calculated for a single time point, it is more common to calculate these measures for a time period. Researchers should note that using different denominators may affect calculations of prevalence, incidence, mortality rates and life expectancy. For example, a military member who visits the hospital for diabetes will not be captured by the CCDSS, because military members are a subgroup of the population who are federally insured. Therefore, the most appropriate denominator to use for calculating a measure of disease frequency would be Statistics Canada's estimates. However, the CCDSS denominator is the most appropriate denominator for estimating measures of disease frequency, when using administrative data (i.e. numerator is derived from CCDSS data).

In addition, a researcher may wish to calculate the prevalence of diabetes in 2006 among Canadians. The researcher could obtain the number of diabetes cases that occurred in 2006 from the CCDSS and may decide to use Statistics Canada's estimates for the denominator (representing the total Canadian population for 2006). However, the risk of outcome for the numerator may not match the Statistics Canada estimates (may not represent this population). Or perhaps an individual with diabetes died before the 2006 census enumeration date, but was registered as a case in the data source before their death. In this scenario, this individual would be accounted for by the numerator, but not in the denominator, thereby resulting in an inaccurate estimate of the prevalence of diabetes in Canada during 2006.

In order to quantify the gaps in missing data in both the CCDSS and Statistics Canada's estimate of population, further research must be conducted on data quality of the health insurance registries and work to quantify subgroups of the population (i.e. emigrants) that are unaccounted for by either data source.

The CCDSS captures nearly the entire Canadian population through the health

TABLE 5

Diabetes prevalence, incidence and mortality rates ${ }^{a}$ by population, Canada, 2009

\begin{tabular}{lccc} 
Statistic & CCDSS denominator ${ }^{\mathrm{b}}$ & $\begin{array}{c}\text { Statistics Canada's } \\
\text { estimates of } \\
\text { population }\end{array}$ & Percent difference, \% \\
\hline Prevalence & 7.2 & 7.5 & -4.0 \\
\hline Incidence & 6.4 per 1000 & 6.6 per 1000 & -3.0 \\
\hline Mortality & Total (without the deaths in the populations) & -3.1 \\
\hline
\end{tabular}

Notes: This study was made possible through collaboration between PHAC and the respective provincial governments of Alberta, British Columbia, Saskatchewan, Manitoba, Ontario, Quebec, New Brunswick, Prince Edward Island, Nova Scotia, Newfoundland and Labrador, and territorial governments of Yukon, Northwest Territories, and Nunavut. The opinions, results and conclusions reported in this paper are those of the authors. No endorsement by British Columbia, Saskatchewan, Manitoba, Ontario, Quebec, New Brunswick, Prince Edward Island, Nova Scotia, Newfoundland and Labrador, Yukon, Northwest Territories, Nunavut is intended or should be inferred.

${ }^{a}$ CCDSS counts were randomly rounded.

${ }^{\mathrm{b}}$ CCDSS denominator data were contributed by provinces and territories, as of November 2015 (v2014).

c Statistics Canada's estimates of population were postcensal (2006 Census). ${ }^{20}$ insurance registry. We recognize that people who move to a new province or territory during a fiscal year (interprovincial migration) and receive valid health insurance are counted twice in the CCDSS denominator, for a limited period of time.

The difference between the adjusted CCDSS denominator and Statistics Canada's estimate (431296 people) may be attributed to the discrepancies of the valid and eligible health numbers defined in the health insurance registries, possibly due to fraud. ${ }^{30}$ In addition, the health insurance registries can include inaccurate information about deaths, due to the time and resources required to process this information..$^{31}$ Statistics Canada has found it challenging to count Canadians who emigrate for work and who are homeless, but the number of these emigrants is estimated to be small. ${ }^{32-35}$ Both the health insurance registries and Statistics Canada staff continue to monitor the data, looking for these issues and finding explanations and mitigation strategies for them. Small differences by age (in the younger age groups) can also be attributed to the different age-at-reference dates between the two data sources. The underestimate found by the Alberta ministry ${ }^{11}$ could be attributed to the different methods used by AHCIP (2006 census data was compared) and Statistics Canada Demography Division (conducting the provincialspecific CCDSS denominator adjustment).

\section{Conclusion}

Our results illustrate the importance of making an informed choice when selecting estimates of population for research, as the selection can have an effect on the calculation of rates. We found that even after adjusting the CCDSS denominator for deaths and interprovincial migration, the CCDSS denominator was greater than the Statistics Canada estimate.

These findings allow researchers to compare the major reasons for the differences between the CCDSS denominator and Statistics Canada's estimate of population in order to select the most appropriate denominator for their projects and measuring disease frequency.

It is our opinion that the CCDSS denominator best represents the population at risk for events identified using health administrative data. The CCDSS denominator should be used to measure disease 
frequency, as it comprises those with valid health insurance over a period. When Statistics Canada's estimates of population were used as the denominator, the exposed population was underestimated, as the census was taken at a point in time; however, people who were deceased or away at that time were included in the period prevalence numerator. Although the magnitude of the differences in diabetes rates between the two sources was small, these findings could have a slight implication on the interpretation and conclusions drawn from previous studies that have estimated prevalence, incidence and mortality using Statistics Canada's estimates of population as population denominator estimates.

\section{Acknowledgements}

We wish to thank the members of the CCDSS Scientific and Technical Committee. This study was made possible through the collaboration of PHAC and the provincial governments of British Columbia, Alberta, Saskatchewan, Manitoba, Ontario, Quebec, New Brunswick, Prince Edward Island, Nova Scotia, Newfoundland and Labrador and the territorial governments of Yukon, Northwest Territories and Nunavut. The opinions, results and conclusions reported in this paper are those of the authors. No endorsement by any government is intended or should be inferred.

\section{References}

1. Moise P. OECD ageing related disease study: using hospital administrative databases for a disease-based approach to studying health care systems [Internet]. Paris (FR): Organisation for Economic Co-operation and Development; 2001 [cited 2015 Jul 17]. Report No.: IAG Y1-AG-8363-01 Available from: http://www.oecd.org/sweden/1889879 .pdf

2. Iron K, Manuel DG. Quality assessment of administrative data (QuAAD): an opportunity for enhancing Ontario's health data [Internet]. Toronto (ON): Institute for Clinical Evaluative Sciences; 2007 [cited 2015 Jul 17]. Available from: http://www .ices.on.ca/ /media/Files/Atlases -Reports/2007/Quality-assessment-of -administrative-data/Full \% 20report .ashx
3. Alaghehbandan R, MacDonald D. Use of administrative health databases and case definitions in surveillance of depressive disorders: a review. OA Epidemiol. 2013;1(3): 1-7. doi: 10.13172 /2053-079x-1-1-539.

4. Robitaille C, Dai S, Waters C, et al. Diagnosed hypertension in Canada. CMAJ. 2012;184(1):E49-56. doi: 10.1503/cmaj.101863.

5. Robitaille C, Bancej C, Dai S, et al. Surveillance of ischemic heart disease should include physician billing claims: population-based evidence from administrative health data across seven Canadian provinces. BMC Cardiovasc Disord. 2013;13:88. doi: 10.1186/1471-2261-13-88.

6. Blais C, Dai S, Waters $C$, et al. Assessing the burden of hospitalized and community-care heart failure in Canada. Can J Cardiol. 2014;30(3): 352-8. doi: 10.1016/j.cjca.2013.12.013.

7. Pelletier C, Dai S, Roberts KC, Bienek A, Onysko J, Pelletier L. Report summary. Diabetes in Canada: facts and figures from a public health perspective. Chronic Dis Inj Can. 2012; 33(1):53-4.

8. Fletcher RW, Fletcher SW. Clinical epidemiology: the essentials. 4th ed. Baltimore (MD): Lippincott Williams \& Wilkins; 2005. 251 p.

9. Statistics Canada. Census of population [Internet]. Ottawa (ON): Statistics Canada; 2012 [cited 2015 Jul 22]. Available from: http://www23.statcan .gc.ca/imdb/p2SV.pl?Function $=$ getSurvey \&SDDS $=3901 \&$ Item_ $\mathrm{Id}=114960 \&$ lang $=$ en

10. Statistics Canada. Population and family estimation methods at Statistics Canada [Internet]. Ottawa (ON): Statistics Canada; 2013 [cited 2015 Jul]. Available from: http://www .statcan.gc.ca/pub/91-528-x/91-528 -x2011001-eng.htm

11. Government of Alberta. Comparison of Alberta population counts between the AHCIP registry and the 2006 census. [Internet]. Edmonton: (AB): Alberta Health and Wellness; 2009 [cited 2015 Jul 22]. Available from: http://www.health.alberta.ca /documents / Population-2006 -Comparison-2009.pdf
12. Alberta Health and Wellness. Health trends Alberta: weekly statistical report [Internet]. Edmonton (AB): Alberta Health and Wellness; 2015 [cited 2015 Dec 22]. Available from: http://www.health.alberta.ca /newsroom/health-trends.html

13. Health Canada. Responding to the challenge of diabetes in Canada: first report of the National Diabetes Surveillance System (NDSS) [Internet]. Ottawa (ON): Health Canada; 2003 [cited 2015 Jul 22]. Available from: http://www.phac-aspc.gc.ca/ccdpc -cpcmc/ndss-snsd/english/pubs_ reports/pdf/NDSS_English_Report_ FINAL.pdf

14. Non-insured health benefits for First Nations and Inuit [Internet]. Ottawa (ON): Government of Canada; [updated 2016 Sept 1; cited 2015 Jul 22]. Available from: http://www.hc -sc.gc.ca/fniah-spnia/nihb-ssna /index-eng.php

15. Health Canada. Federal role in health [Internet]. Ottawa (ON): Health Canada; [modified 2005 Oct 7; cited 2015 Jul 22]. Available from: http:// www.hc-sc.gc.ca/hcs-sss/delivery -prestation/fedrole/index-eng.php\#a1

16. Statistics Canada. Estimates of population coverage error [Internet]. Ottawa (ON): Statistics Canada; 2010 Aug 3 [cited 2015 Jul 22]. Available from: http://www12.statcan.gc.ca / census-recensement/2006/ref /rp-guides/rp/coverage-couverture /cov-couv_p01-eng.cfm

17. Statistics Canada. 2011 Census collection [Internet]. Ottawa (ON): Statistics Canada; [cited 2015 Jul 22]. Available from: http://www12 .statcan.gc.ca/census-recensement /2011/ref/about-apropos/col-eng.cfm

18. Statistics Canada. Differences between Statistics Canada's census counts and population estimates [Internet]. Ottawa (ON): Statistics Canada; [cited 2015 Jul 22]. Available from: http://www. statcan.gc.ca/hp-pa/estima-eng.htm

19. Statistics Canada. 2006 Census technical report: coverage [Internet]. Ottawa (ON): Minister of Industry; 2010 [cited 2015 Jul 22]. Available from: http://www12.statcan.ca /census-recensement/2006/ref/rp -guides/rp/coverage-couverture/cov -couv_index-eng.cfm 
20. Statistics Canada. Population estimates by year, by province and territory (Number) [Internet]. Ottawa (ON): Statistics Canada; 2012 [cited 2015 Jul 22]. Available from: http:// www.statcan.gc.ca/tables-tableaux /sum-som/101/cst01/demo02a-eng. htm

21. Statistics Canada. Migration estimates - user guide [Internet]. Ottawa (ON): Statistics Canada; 2011 Sep 22 [cited 2015 Jul 22]. Available from: http:// www23.statcan.gc.ca/imdb-bmdi /document/4101_D3_T1_V8-eng.htm

22. Statistics Canada. The population and family estimation methods at Statistics Canada. Ottawa (ON): Statistics Canada; 2003 Apr. Available from: http://publications.gc.ca/ Collection-R/Statcan/91-528-XIE /0010391-528-XIE.pdf

23. Statistics Canada. Table 051-0013. Estimates of births, by sex, Canada, provinces and territories, annual (persons) [Internet]. Ottawa (ON): Statistics Canada; [cited 2015 Jun 9]. Available from: http://www5.statcan .gc.ca/cansim/a26?lang = eng\&id $=510013$

24. Statistics Canada. Table 051-0063. Components of population growth by census division, sex and age group for the period from July 1 to June 30, based on the Standard Geographical Classification (SGC) 2011, annual (persons) [Internet]. Ottawa (ON): Statistics Canada; [cited 2015 Jun 9]. Available from: http://www5.statcan. gc.ca/cansim/a26?lang=eng\&id $=510063$

25. Statistics Canada. Table 051-0012. Interprovincial migrants, by age group and sex, Canada, provinces and territories, annual (persons) [Internet]. Ottawa (ON): Statistics Canada; [cited 2015 June 9]. Available from: http://www5.statcan.gc.ca /cansim/a26?lang = eng\&id $=510012$

26. Statistics Canada. Annual demographic estimates: Canada, provinces and territories [Internet]. Ottawa (ON): Statistics Canada; 2012 [cited 2015 Jul 22]. Available from: http:// www.statcan.gc.ca/pub/91-215-x/91 -215-x2012000-eng.pdf
27. Statistics Canada. Table 051-0002. Estimates of deaths, by sex and age group, Canada, provinces and territories; 2013 edition [Internet]. Ottawa (ON): Statistics Canada; [cited 2015 Jul 22]. Available from: http://www5 .statcan.gc.ca/cansim/a26?lang = eng\&retrLangeng\&id $=0510002$ \&paSer $=\&$ pattern $=\&$ stByVal $=1 \&$ p 11 $\&$ p2 $=31 \&$ tabModedataTable \&csid

28. Chiang CL. The life table and its applications. Malabar (FL): Robert E. Krieger Publishing Company; 1984. $336 \mathrm{p}$.

29. Hsieh JJ. A general theory of life construction and a precise abridged life table method. Biom J. 1991;33(2); 143-62.

30. Ontario Ministry of Health and LongTerm Care. OHIP fraud [Internet]. Toronto (ON): 2009 Apr [cited 2015 Dec 22]. Available from: http://www .health.gov.on.ca/en / public /publications/ohip/card_fraud.aspx

31. Iron $\mathrm{K}$, Zagorski BM, Sykora $\mathrm{K}$, Manuel DG. Living and dying in Ontario: an opportunity for improved health information [Internet]. Toronto (ON): Institute for Clinical Evaluative Sciences; 2008 Mar [cited 2015 Dec 22]. Available from: http://www.ices .on.ca/Publications/Atlases-and -Reports/2008/Living-and-dying -in-Ontario

32. DeVoretz DJ. Immigrant circulation and citizenship: Hotel Canada? Project Paper Series No. 09-04:1-19 [Internet]. Vancouver (BC): Asia Pacific Foundation of Canada; 2009 [cited 2015 Jul 17]. Available from: http://www.asiapacific.ca/sites/ default/files/filefield/PP_09_4_DD_ HotelCanada.pdf

33. DeVoretz DJ. Canada's secret province: 2.8 million Canadians abroad. Project Paper Series No. 09-05 [Internet]. Vancouver (BC): Asia Pacific Foundation of Canada; 2009 [cited 2015 Jul 17]. Available from: http://www.asiapacific.ca/research -report/canadas-secret-province-28 -million-canadians-abroad
34. Gaetz S, Gulliver T, Richter T. The state of homelessness in Canada 2014 [Internet]. Toronto (ON): Canadian Homelessness Research Network Press; 2014 [cited 2015 Jul 17]. Available from: http://www .homelesshub.ca/sites/default/files /SOHC2014.pdf

35. Hwang SW. Homelessness and health. CMAJ. 2001;164(2);229-33. 